\title{
Depression in small-vessel disease relates to white matter ultrastructural damage, not disability OPEN
}

Rebecca L. Brookes, PhD Vanessa Herbert, MSc Andrew J. Lawrence, PhD Robin G. Morris, PhD Hugh S. Markus, DM, FRCP

Correspondence to Dr. Brookes: rbrookes@sgul.ac.uk

Supplemental data at Neurology.org

\section{ABSTRACT}

Objective: To determine whether cerebral small-vessel disease (SVD) is a specific risk factor for depression, whether any association is mediated via white matter damage, and to study the role of depressive symptoms and disability on quality of life (QoL) in this patient group.

Methods: Using path analyses in cross-sectional data, we modeled the relationships among depression, disability, and QoL in patients with SVD presenting with radiologically confirmed lacunar stroke $(n=100)$, and replicated results in a second SVD cohort $(n=100)$. We then compared the same model in a non-SVD stroke cohort $(n=50)$ and healthy older adults $(n=203)$. In a further study, to determine the role of white matter damage in mediating the association with depression, a subgroup of patients with SVD $(n=101)$ underwent diffusion tensor imaging (DTI).

Results: Reduced QoL was associated with depression in patients with SVD, but this association was not mediated by disability or cognition; very similar results were found in the replication SVD cohort. In contrast, the non-SVD stroke group and the healthy older adult group showed a direct relationship between disability and depression. The DTI study showed that fractional anisotropy, a marker of white matter damage, was related to depressive symptoms in patients with SVD.

Conclusion: These results suggest that in stroke patients without SVD, disability is an important causal factor for depression, whereas in SVD stroke, other factors specific to this stroke subtype have a causal role. White matter damage detected on DTI is one factor that mediates the association between SVD and depression. Neurology ${ }^{\circledR}$ 2014;83:1417-1423

\section{GLOSSARY}

$\mathbf{A D L}=$ Activities of Daily Living; $\mathbf{B M E T}=$ Brief Memory and Executive Test $; \mathbf{C l}=$ confidence interval; $\mathbf{D T I}=$ diffusion tensor imaging; EPI = echo planar image; FA = fractional anisotropy; GDS = Geriatric Depression Scale; IADL = Instrumental Activities of Daily Living; $\mathbf{m R S}$ = modified Rankin Scale; QoL = quality of life; SCANS = St George's Cognition and Neuroimaging in Stroke; SSQ $\mathbf{L}=$ Stroke-Specific Quality of Life Scale; SVD = small-vessel disease.

Cerebral small-vessel disease (SVD) results from damage to small perforating end arteries supplying white matter and subcortical gray matter, and is characterized by lacunar infarcts and leukoaraiosis. Common features include lacunar stroke, cognitive impairment, and reduced quality of life (QoL). ${ }^{1,2}$ More recently, depression ${ }^{3}$ has been associated with SVD, and can occur before the onset of other symptoms. ${ }^{4}$

It has been hypothesized that SVD may predispose individuals to depression by disruption of cortical-subcortical circuits underlying mood. ${ }^{5}$ White matter lesions are more common in lateonset depression compared with nondepressed controls, ${ }^{6-8}$ and lacunar infarcts and leukoaraiosis are risk factors for chronic poststroke depression. ${ }^{9-11}$ However, not all studies confirm these associations ${ }^{12-15}$; one possible reason is that other variables, such as physical disability and cognitive impairment, may mediate the relationship between stroke and depression. ${ }^{16}$

Depression is common after all subtypes of stroke, and relates to the degree of disability. ${ }^{17}$ If SVD has a specific causal role in depression via disruption of cortical-subcortical circuits, one would predict an association between depression and SVD stroke that persists after controlling

From the Stroke and Dementia Research Centre (R.L.B., V.H., A.J.L.), St George's, University of London; University of Cambridge (H.S.M.),

Department of Neurology, Cambridge Biomedical Campus; and Department of Psychology (R.G.M.), Institute of Psychiatry, King's College London, UK. Go to Neurology.org for full disclosures. Funding information and disclosures deemed relevant by the authors, if any, are provided at the end of the article. The Article Processing Charge was paid by the Wellcome Trust.

This is an open access article distributed under the Creative Commons Attribution License, which permits unrestricted use, distribution, and reproduction in any medium, provided the original work is properly cited. 
for the degree of physical disability. However, in non-SVD stroke, depression would be related to the degree of physical disability with the association attenuated after controlling for disability. To address this question, we first compared structural equation models of depression in SVD and non-SVD stroke samples. Next, we used diffusion tensor imaging (DTI) to investigate the hypothesis that the SVD-depression association is mediated by white matter damage.

METHODS Study design. Cross-sectional observational investigation of structural equation models in SVD, non-SVD stroke, and healthy control groups.

SVD population. SVD was defined as a clinical lacunar stroke syndrome ${ }^{18}$ with radiologic (MRI) confirmation of an anatomically corresponding lacunar infarct seen on diffusion-weighted imaging for acute MRI, or for nonacute MRI ( $>2$ weeks poststroke) by a hypodense region on $\mathrm{T} 1$ or fluid-attenuated inversion recovery sequences consistent with lacunar infarction of $<1.5 \mathrm{~cm}$ diameter. Exclusion criteria included inability or unwillingness to consent, and evidence of any stroke mechanism other than SVD: any cortical infarction, subcortical infarcts $>1.5 \mathrm{~cm}$ in diameter, cardioembolic source, and extracranial or intracranial large-artery stenosis (>50\%). For all patients with SVD, assessments were performed $>3$ months poststroke to reduce acute effects of ischemia on cognitive and other measures. Two SVD cohorts (discovery and replication) were recruited. Both had identical inclusion and exclusion criteria. Thirty percent of all patients with SVD met the Geriatric Depression Scale (GDS) criteria for depression. ${ }^{19}$ Sample size for the discovery cohort was chosen to provide a sample comparable to that used in a previous report on depression in SVD. ${ }^{3}$

Discovery cohort. One hundred patients (60 male; mean [SD] age 71.1 [8.5] years) were recruited from specialized stroke services in 3 district hospitals in South London, UK, between March 2007 and September 2009. These formed part of the early recruitment to the St George's Cognition and Neuroimaging in Stroke $\left(\mathrm{SCANS}^{20}\right)$ Study and the Brief Memory and Executive Test $\left(B^{M} \mathrm{TT}^{21}\right)$ Study.

Replication cohort. One hundred patients (71 male; mean [SD] age 65.1 [9.9] years) were recruited from specialized stroke services across the United Kingdom as part of 2 ongoing studies determining cognitive impairment in SVD (SCANS ${ }^{20}$ and BMET multicenter extension). For both studies, recruitment was from acute stroke units and outpatient minor stroke/TIA services between September 2009 and November 2013

Non-SVD ischemic stroke population. Fifty patients with nonlacunar ischemic stroke (28 male; mean [SD] age 63.5 [11.6] years), matched for disability level with the SVD cohorts, were recruited from stroke clinics at St George's Hospital, London, between November 2010 and February 2013. Inclusion criteria were any cortical infarction (with or without associated subcortical infarction), or nonlacunar subcortical infarction $>2 \mathrm{~cm}$ in maximum diameter. Exclusion criteria included Fazekas leukoaraiosis grade $>1$ on MRI. ${ }^{22}$ All cases were reviewed by a single consultant neurologist and classified according to the TOAST (Trial of Org 10172 in Acute Stroke Treatment) stroke classification ${ }^{23}$ : large-artery $=14 \%$; cardioembolic $=26 \%$; other $=6 \%$; and unknown $=54 \%$. Review of MRIs showed that 35 (70\%) had cortical infarction, and $15(30 \%)$ had nonlacunar subcortical infarction. No patients were tested during the acute stroke phase; 43 (86\%) were tested at least 3 months poststroke, and all were tested at least 6 weeks poststroke. Twenty percent of the non-SVD stroke patients met the GDS criteria for depression. ${ }^{19}$

Healthy control population. A control group (85 male; mean [SD] age 67.1 [9.4] years), consisting of 203 healthy individuals without previous stroke or other major neurologic disorder, was recruited by random sampling of family doctor practices in South London between January 2012 and January 2013. All patients in the United Kingdom are registered with a family doctor and therefore this is representative of the community population. Eleven percent of the control population met the GDS criteria for depression.

DTI SVD subgroup. A subset of patients with SVD ( $\mathrm{n}=101)$, 66 from the discovery cohort and 35 from the replication cohort, all from the SCANS Study, ${ }^{20}$ underwent DTI in addition to conventional MRI, as well as an extensive cognitive and functional disability assessment.

Demographics of the patient and control groups are shown in table 1 .

Study protocol approvals, registrations, and patient consents. All research was conducted as a part of studies approved by a UK NHS ethics committee. Full written consent was obtained from all participants.

Behavioral measures. All patient and control groups were assessed using the same scales as follows. Depression was assessed using the 30-item GDS. ${ }^{19}$ This includes items with yes/no responses: for example, "Do you feel that your life is empty?" and "Are you in good spirits most of the time?" Data on depressive symptoms were collected on a continuous scale of 0 to 30 rather than a binary scale of depressed vs not depressed, so as to retain maximum variance in the data.

QoL was assessed using the Stroke-Specific Quality of Life Scale $\left(\mathrm{SSQoL}^{24}\right)$. This scale was developed for use in stroke trials with established internal reliability and sensitivity to change. For the purpose of this study, the scale items were presented in the present tense to reflect current experiences (e.g., "I often have to stop and rest during the day"). Total QoL score was based on 11 of the 12 subscales (without the mood subscale to avoid overlap with the depression scale). Scores were calculated pro-rata to account for intermittent missing responses.

Disability was measured using the modified Rankin Scale $\left(\mathrm{mRS}^{25}\right)$, a 7-point rating scale developed specifically to measure disability during stroke, and the Barthel Activities of Daily Living $\left(\mathrm{ADL}^{26}\right)$ Scale, which covers levels of basic physical function and independent living. For the subgroup of patients with SVD in study 2, two additional aspects of behavior were assessed ( $\mathrm{n}=101$; see table 1$)$ : higher-order living skills, measured using the Instrumental Activities of Daily Living (IADL) Scale (see reference 27), which focuses on abilities such as managing finances or using public transportation; and global cognition, which was tested using a broad cognitive assessment undertaken by a neuropsychologist at the same time as measuring other indices of function, producing an overall index of performance across all tasks, as summarized in table e-1 on the Neurology ${ }^{\circledR}$ Web site at Neurology.org.

Diffusion tensor imaging. DTI data were acquired on a $1.5 \mathrm{~T}$ General Electric Signa HDxt MRI system (General Electric, Milwaukee, WI) as previously reported. ${ }^{20}$ Axial single-shot spin echo planar images (EPIs) (echo time $=93.4$ milliseconds; repetition time $=$ 15,600 milliseconds) were acquired to give isotropic voxels and whole brain coverage $\left(2.5 \mathrm{~mm}^{3}\right.$; field of view $=240 \times 240 \mathrm{~mm}^{2}$; acquisition matrix $=96 \times 96$ ). After 4 acquisitions without 
Table 1 Patient demographics and results from the different assessments

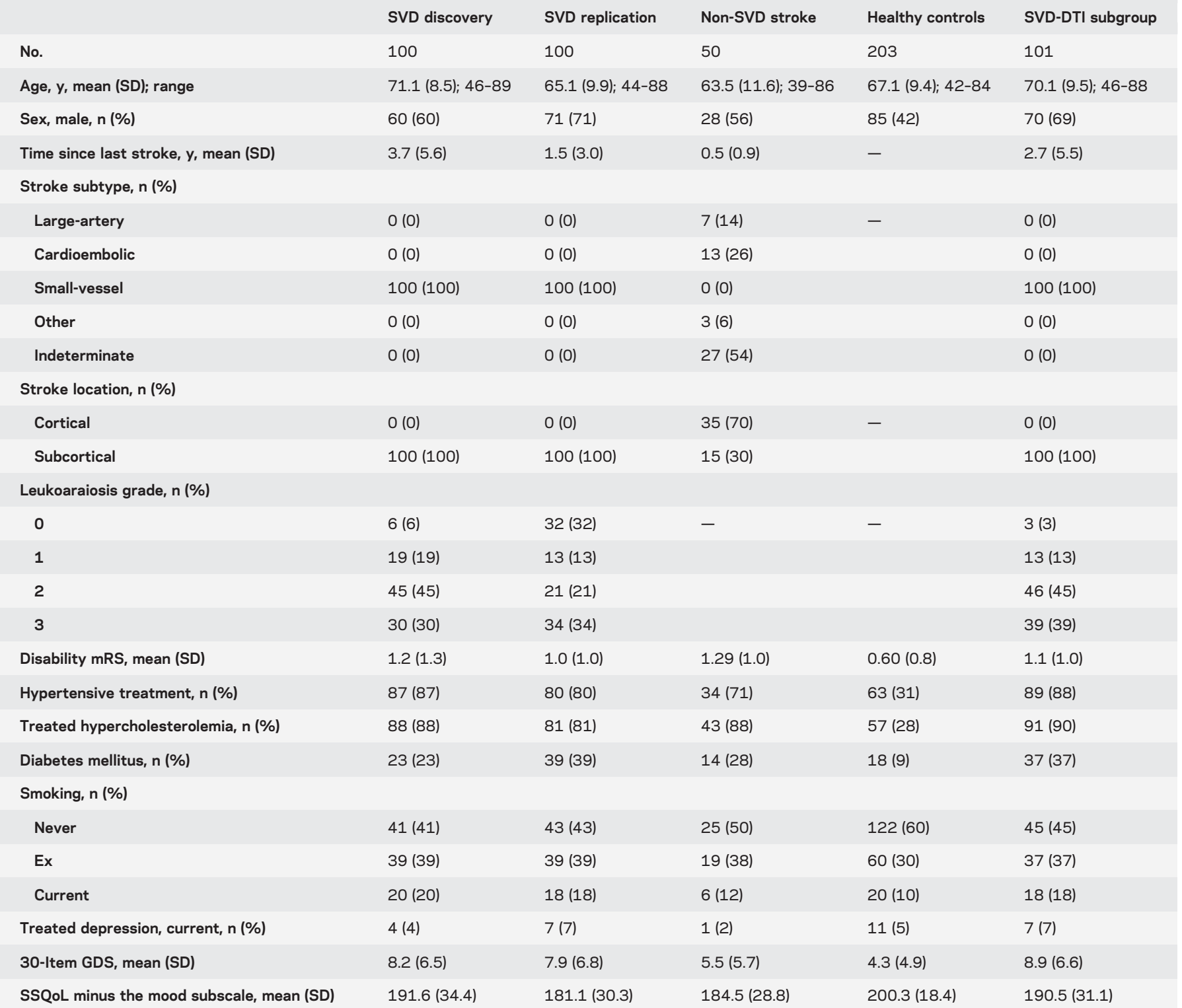

Abbreviations: DTI = diffusion tensor imaging; GDS = Geriatric Depression Scale; $m R S$ = modified Rankin Scale; SSQoL = Stroke-Specific Quality of Life Scale; SVD $=$ small-vessel disease.

diffusion weighting $\left(b=0 \mathrm{~s} \cdot \mathrm{mm}^{-2}\right)$, diffusion-sensitized images were acquired with gradients applied $\left(b=1,000 \mathrm{~s} \cdot \mathrm{mm}^{-2}\right)$ in 25 noncollinear directions. This was repeated to acquire a further 4 $\mathrm{b}=0 \mathrm{~s} \cdot \mathrm{mm}^{-2}$ images and the negative of the 25 directions. The 8 $\mathrm{b}=0 \mathrm{~s} \cdot \mathrm{mm}^{-2}$ images were coregistered and averaged to give a T2-weighted EPI, which was used to realign diffusion images and remove eddy-current distortions using the FSL Linear Image Registration Tool (FLIRT, FMRI Software Library, FSL version 4.1; FMRIB Analysis Group, Oxford, UK, http://www.fmrib.ox. ac.uk/fsl). ${ }^{28}$ The geometric average of the positive and negative acquisitions was taken to eliminate gradient cross-terms. ${ }^{29}$

FSL's TBSS software ${ }^{30}$ was used to analyze diffusion data. EPIs were brain-extracted using BET (Brain Extraction Tool) and fractional anisotropy (FA) images created by fitting a tensor model using FDT. All subjects' FA data were then nonlinearly aligned into a common space and then projected to a mean FA skeleton. Median FA was calculated as the 50th percentile of nonzero voxels from each subject's TBSS skeleton. We used median FA as an index of white matter structural integrity throughout the whole brain.

Statistical analysis. Variables were corrected such that higher values equated to higher levels of depressive symptoms, disability, functional disability, and cognitive deficit, and lower levels of QoL and white matter integrity. Missing data were examined and found to be few and sporadic (SSQoL $=0.4 \%$; 30-item $\mathrm{GDS}=2.4 \% ; \mathrm{mRS}=0.4 \% ; \mathrm{ADL}=0.6 \%$, $\mathrm{ADL}=1 \%$; median $\mathrm{FA}=0 \%$; global cognition $=0 \%$ ). Therefore, these data were imputed using an expectation maximization algorithm, as part of SPSS's Missing Value Analysis Tool, for each variable and group separately.

Study 1. To investigate simultaneously the relationships among disability, depression, and QoL for each study population, analyses were performed using AMOS 5.0 SEM (structural equation modeling) software. Disability was defined as a latent variable with loadings from 2 disability measures, ADL and mRS. 
Depression and QoL were defined as observed variables with total scores taken from the 30-item GDS and SSQoL, respectively. The variance in the endogenous variables accounted for by age and sex was controlled for in the models. Each model had 21 sample moments and 15 parameters to be estimated $=6$ degrees of freedom. For robustness and to account for any nonnormality in the data, bootstrap analyses (using nonparametric resampling, 2,000 repetitions) were conducted for direct and indirect effects in the model.

Study 2. An extended model using the DTI data was created to determine the role of loss of white matter integrity on depression and disability, as well as the role of IADL and global cognition. For this analysis, a subgroup of patients with SVD taken from the discovery and replication cohorts were included $(\mathrm{n}=101$, age 70.1 [9.5] years, sex 70 male; see table 1). The extended model had 28 sample moments and 22 parameters to be estimated $=6$ degrees of freedom For robustness and to account for any nonnormality in the data, bootstrap analyses (using nonparametric resampling, 2,000 repetitions) were conducted for direct and indirect effects in the model.

RESULTS Study 1: Depression, disability, and QoL. We hypothesized in our initial theoretical model that

\section{Figure 1 SVD models}

\section{A. SVD exploratory model}

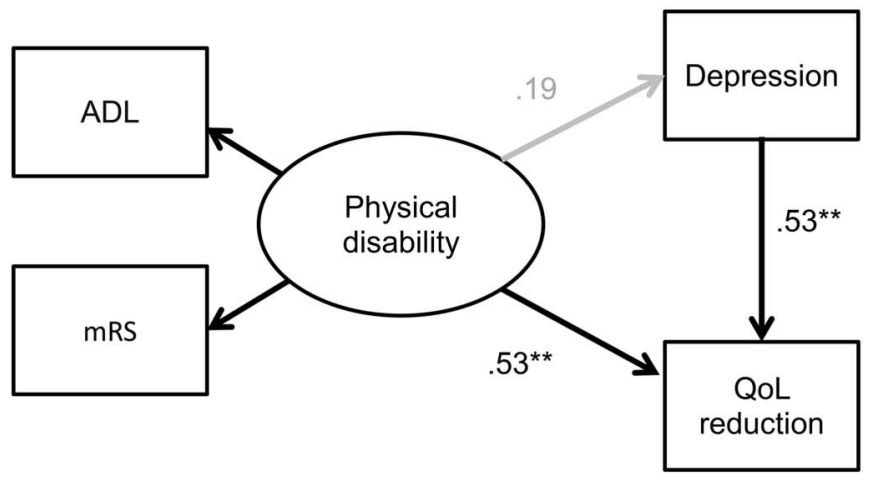

\section{B. SVD replication model}

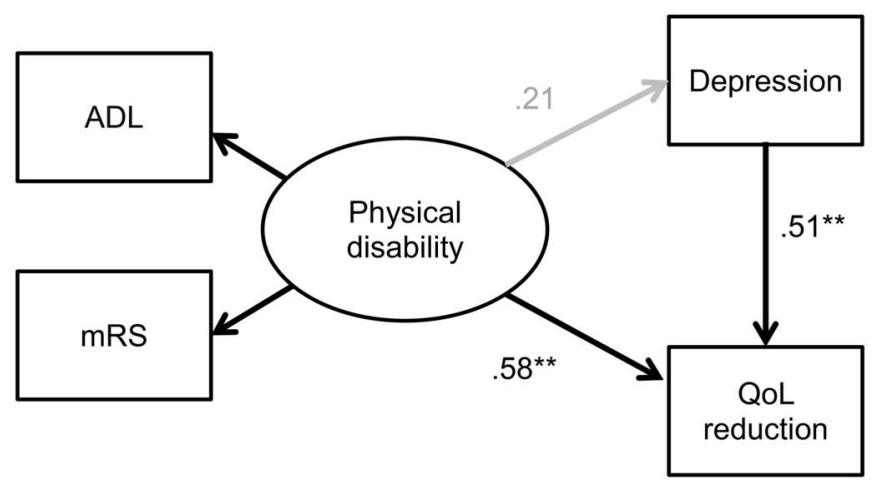

(A) SVD exploratory model of the relationships among physical disability, depression, and reduction in QoL, in SVD. (B) SVD replication analysis of model 1 in a second independent SVD patient group. Standardized $\beta$ weights are shown for each path. $* *$ Significant at the 0.001 level. For depression, higher = worse depression; QoL reduction, higher = poorer QoL; disability, higher $=$ worse disability. $A D L=$ Activities of Daily Living; $m R S=$ modified Rankin Scale; QoL = quality of life; SVD = small-vessel disease. in SVD, both depression and disability would directly affect QoL, and that disability would affect depression leading to an indirect effect on QoL. We also included age and sex in the model to account for group differences.

SVD discovery cohort. Path analyses indicated that the direct path from depression to QoL was highly significant $(\beta=0.53, p<0.001 ; 95 \%$ confidence interval $[\mathrm{CI}]=0.41,0.64)$ as was the direct path from disability to $\mathrm{QoL}(\beta=0.53, p<0.001 ; 95 \% \mathrm{CI}=0.41,0.66)$. However, the direct path between disability and depression was not significant $(\beta=0.19, p=0.08 ; 95 \% \mathrm{CI}=$ $-0.02,0.41)$. The indirect path from disability to $\mathrm{QoL}$ via depression was not significant $(\beta=0.10, p=0.06$; $95 \% \mathrm{CI}=-0.01,5.8$.

SVD replication cohort. The initial model was applied to the replication SVD cohort. Path analyses revealed a very similar pattern of results to that seen in the discovery cohort. The direct paths from depression to QoL $(\beta=0.51, p<0.001 ; 95 \%$ CI $=0.36$, $0.67)$ and disability to $\mathrm{QoL}(\beta=0.58, p<0.001$; $95 \% \mathrm{CI}=0.37,0.78)$ were highly significant with similar $\beta$ values to the discovery group. The direct path between disability and depression was not significant $(\beta=0.21, p=0.15 ; 95 \% \mathrm{CI}=-0.07$, $0.49)$ and the indirect path from disability to QoL via depression was also not significant $(\beta=0.11, p=$ $0.13 ; 95 \% \mathrm{CI}=-0.03,0.13)$. See figure 1 .

Non-SVD ischemic stroke. When the same model was applied to the non-SVD stroke group, there was a different pattern of results to that seen in SVD. The direct path from depression to QoL was highly significant $(\beta=0.67, p<0.001 ; 95 \% \mathrm{CI}=0.22$, 0.88 ) and the direct path from disability to QoL was significant $(\beta=0.25, p<0.05 ; 95 \% \mathrm{CI}=0.01$, $0.57)$. In addition, the non-SVD group showed a highly significant path from disability to depression $(\beta=0.47, p<0.05 ; 95 \% \mathrm{CI}=0.07,0.74)$ and $\mathrm{a}$ significant indirect path from disability to QoL via depression $(\beta=0.31, p=0.01 ; 95 \% \mathrm{CI}=0.13$, $0.55)$. See figure 2 .

Control group. The results for the control group showed significant paths from depression to $\mathrm{QoL}(\beta=0.45, p=$ 0.003 ; $95 \% \mathrm{CI}=0.26,0.60)$, disability to $\mathrm{QoL}(\beta=$ $0.43, p=0.002 ; 95 \% \mathrm{CI}=0.23,0.63)$, and from disability to depression ( $\beta=0.32, p=0.007 ; 95 \%$ $\mathrm{CI}=0.10,0.59)$. There was also a significant indirect effect of disability on QoL via depression ( $\beta=0.14, p=$ 0.004; $95 \% \mathrm{CI}=0.05,0.26$ ). See figure 3 .

Time from stroke analysis. Because time from last stroke was not matched between groups, a regression analysis was performed in SPSS version 19 (IBM Corp., Armonk, NY) to determine whether time from stroke had an effect on depression. The results 


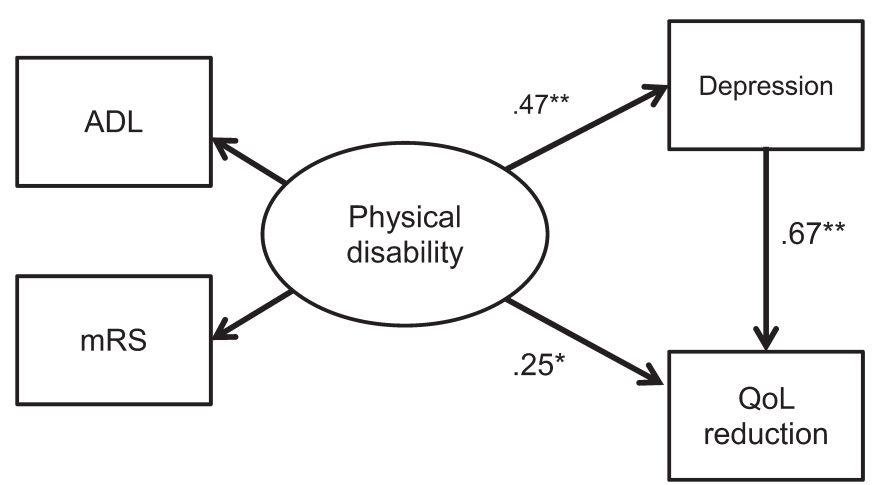

Replication analysis in a non-SVD stroke patient group. Standardized $\beta$ weights are shown for each path. *Significant at the 0.05 level; **significant at the 0.001 level. ADL = Activities of Daily Living; mRS = modified Rankin Scale; QoL = quality of life; SVD = small-vessel disease.

Figure 3 Control model

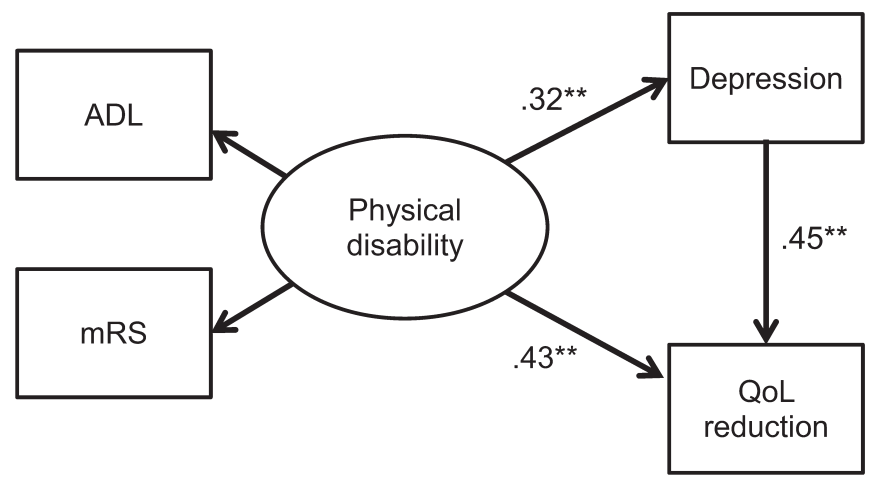

Replication analysis in a healthy older adult group. Standardized $\beta$ weights are shown for each path. ${ }^{*}$ Significant at the 0.001 level. $A D L=$ Activities of Daily Living; $m R S=$ modified Rankin Scale; QoL = quality of life. $(\beta=0.09, p=0.005 ; 95 \% \mathrm{CI}=0.02,0.19)$. See figure 4 .

DISCUSSION The results of study 1 demonstrated that, in SVD, depression had a major effect on QoL, as did physical disability. However, the magnitude of the depressive symptoms was not significantly related to the degree of disability in this population. This was confirmed in a replication analysis of an independent sample, with strikingly similar results. By contrast, the same analysis in a stroke population in whom stroke was due to causes other than SVD and in whom radiologic evidence of SVD was excluded on MRI, found a significant relationship between depressive symptoms and degree of physical disability, in addition to the relationship between depression and QoL and disability and QoL. Taken together, these findings suggest that in stroke patients without SVD, disability is an important causal factor in depression, while in SVD stroke, other factors specific to this stroke subtype have a causal role.

The results of study 2, which included DTI to measure white matter ultrastructural damage, support the hypothesis that one factor that explains the specific association of SVD with depression is white matter damage. When median FA, an index of global white matter integrity, was added to the model along with global cognition and functional disability, the results showed that loss of white matter integrity was associated with depressive symptoms. In addition, FA had a significant direct effect on physical disability and global cognition, a significant indirect effect on QoL via physical disability and depression, and a significant indirect effect on functional disability via global cognition. These findings highlight the major impact of white matter damage on function, and are consistent with white matter tract disruption having a direct role in depression in patients with SVD.

Previous studies have reported that white matter hyperintensities are associated with late-onset depression ${ }^{31}$ and have shown that radiologic evidence of SVD is associated with depression in stroke populations. ${ }^{10,11}$ These results have been used to suggest that white matter ischemia and subsequent white matter tract damage produces disruption of cortical-subcortical connections underlying complex networks involved in mood regulation. ${ }^{32,33}$ Understanding the interrelationships of other factors such as physical disability on SVD and depression is complex, and studies have shown mixed results. ${ }^{3,16}$ In this report, we identified differential models of depression, disability, and QoL in stroke populations with and without SVD, and demonstrated the direct role of white matter damage on depression in an SVD population. These findings suggest that SVD may have a direct role in driving depression. Further studies focused on specific regions are required to better 
Figure 4 Extended SVD model including functional disability, global cognitive deficit, and white matter damage (taken as median FA with signs reversed)

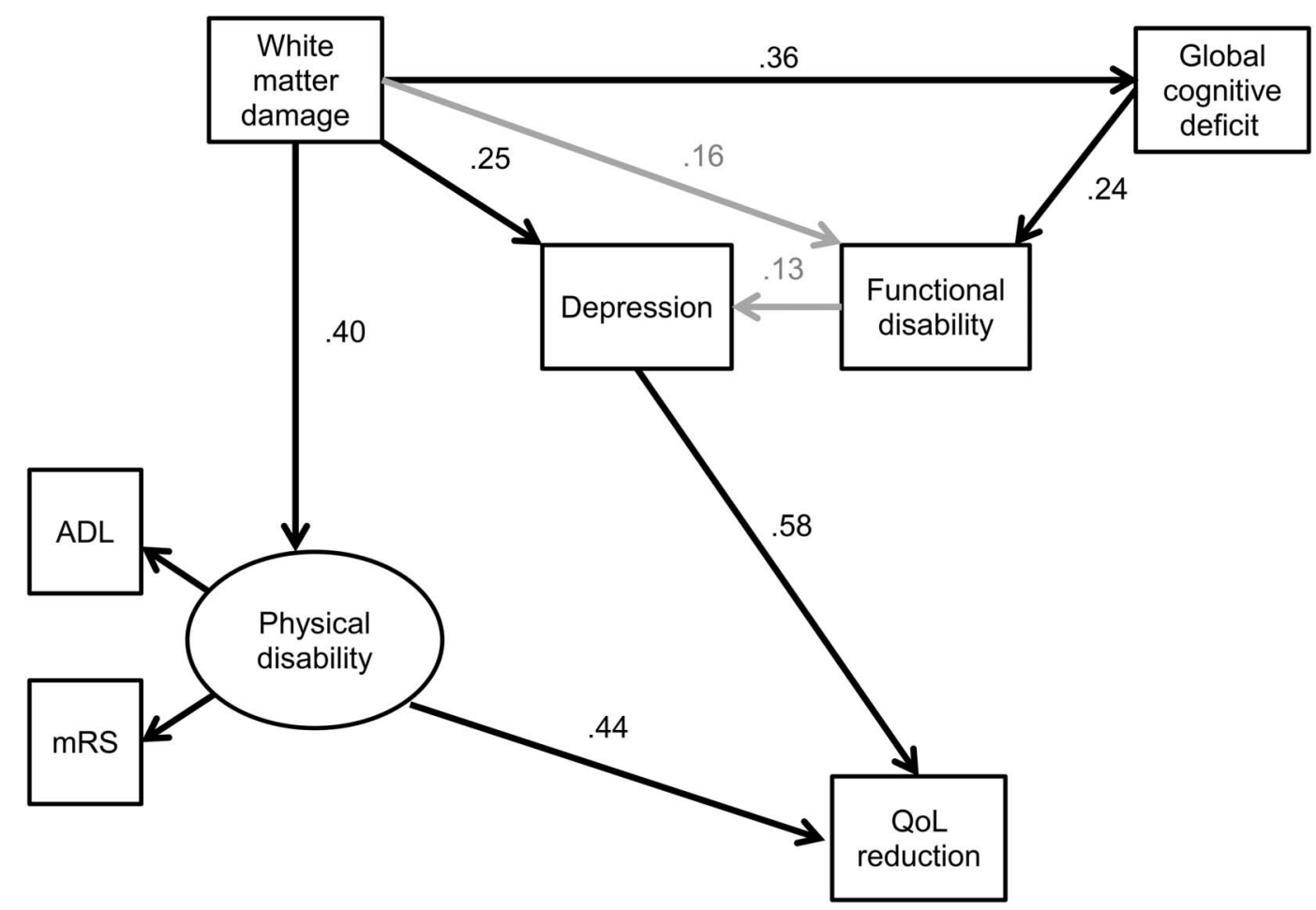

Standardized $\beta$ weights are shown for each path. For clarity, only paths significant at the 0.05 level are presented in black, and paths approaching significance are presented in gray. ADL = Activities of Daily Living; FA = fractional anisotropy; $\mathrm{mRS}=$ modified Rankin Scale; QoL = quality of life; SVD = small-vessel disease

understand the disruption of specific pathways and may provide further evidence for the vascular depression hypothesis.

Our results have some clinical implications. First, they highlight that both depression and disability lead to significant reductions in QoL across stroke subtypes. This is important given the high rates of patients meeting the clinical criteria for depression in our sample compared with the numbers receiving treatment. Second, they suggest that mood may be an important outcome of SVD.

The use of subjective measures, such as the GDS and the SSQoL, may produce a reporting bias related to the presence of anosognosia, or neglect associated with right hemisphere lesions. This is not an issue in the group of patients with SVD, who do not display these symptoms, but could influence results in the stroke group.

SVD appears to be a specific risk factor for depression, independent of disability levels, and this association is at least partially mediated by reduced white matter integrity. Furthermore, expectations that depression results from physical or cognitive disability may contribute to the underrecognition of depression in this patient group. Depression is an important consequence of SVD, and further studies to understand the mechanisms of depression in this population as well as treatment trials may result in improved QoL in this patient group.

\section{AUTHOR CONTRIBUTIONS}

R.L.B. and H.S.M. contributed substantially to the design of the study. R.L.B., V.H., A.J.L., R.G.M., and H.S.M. contributed to the interpretation and preparation of the manuscript. Neuroimaging data were acquired and processed by A.J.L. Behavioral data for the SCANS cohort were acquired and interpreted by A.J.L. and R.G.M. Behavioral data for the BMET cohort were acquired and interpreted by R.L.B. and V.H. Data analysis was completed by R.L.B. The study was supervised by H.S.M. and R.G.M.

\section{ACKNOWLEDGMENT}

The authors thank Selina Paul, Dr. Bhavini Patel, and Dr. Tom Willis for help with data collection, Dr. Tom Barrick for designing the MRI sequences for the SCANS cohort, and Professor Tony Rudd for helpful discussions.

\section{STUDY FUNDING}

This research was supported by grants from the Stroke Association (TSA 2006/12; TSA 2010/08) and the Wellcome Trust (081589/Z/06/Z). Recruitment to both the BMET and SCANS studies was supported by the English National Institute for Health Research (NIHR) Clinical Stroke Research Network. Hugh Markus is supported by an NIHR Senior Investigator award.

\section{DISCLOSURE}

The authors report no disclosures relevant to the manuscript. Go to Neurology.org for full disclosures.

Received December 17, 2013. Accepted in final form June 30, 2014. 


\section{REFERENCES}

1. Roman GC, Erkinjuntti T, Wallin A, Pantoni L, Chui HC. Subcortical ischaemic vascular dementia. Lancet Neurol 2002;1:426-436.

2. O'Brien JT, Erkinjuntti T, Reisberg B, et al. Vascular cognitive impairment. Lancet Neurol 2003;2:89-98.

3. Brookes RL, Willis TA, Patel B, Morris RG, Markus HS Depressive symptoms as a predictor of quality of life in cerebral small vessel disease, acting independently of disability: a study in both sporadic small vessel disease and CADASIL. Int J Stroke 2013;8:510-517.

4. Desmond DW, Moroney JT, Lynch T, Chan S, Chin SS, Mohr JP. The natural history of CADASIL: a pooled analysis of previously published cases. Stroke 1999;30:1230-1233.

5. Taylor WD, Aizenstein HJ, Alexopoulos GS. The vascular depression hypothesis: mechanisms linking vascular disease with depression. Mol Psychiatry 2013;18:963-974.

6. Allan CL, Sexton CE, Kalu UG, et al. Does the Framingham Stroke Risk Profile predict white-matter changes in late-life depression? Int Psychogeriatr 2012;24:524-531.

7. Alves GS, Karakaya T, Fusser F, et al. Association of microstructural white matter abnormalities with cognitive dysfunction in geriatric patients with major depression. Psychiatry Res 2012;203:194-200.

8. Sexton CE, Le Masurier M, Allan CL, et al. Magnetic resonance imaging in late-life depression: vascular and glucocorticoid cascade hypotheses. Br J Psychiatry 2012;201: 46-51.

9. Tang WK, Chen YK, Lu JY, et al. White matter hyperintensities in post-stroke depression: a case control study. J Neurol Neurosurg Psychiatry 2010;81:1312-1315.

10. Kim JT, Park MS, Yoon GJ, et al. White matter hyperintensity as a factor associated with delayed mood disorders in patients with acute ischemic stroke. Eur Neurol 2011; 66:343-349.

11. Mok VC, Wong A, Wong K, et al. Executive dysfunction and left frontal white matter hyperintensities are correlated with neuropsychiatric symptoms in stroke patients with confluent white matter hyperintensities. Dement Geriatr Cogn Disord 2010;30:254-260.

12. Dotson VM, Zonderman AB, Kraut MA, Resnick SM. Temporal relationships between depressive symptoms and white matter hyperintensities in older men and women. Int J Geriatr Psychiatry 2013;28:66-74.

13. Santos M, Gold G, Kovari E, et al. Neuropathological analysis of lacunes and microvascular lesions in late-onset depression. Neuropathol Appl Neurobiol 2010;36:661-672.

14. Rainer MK, Mucke HA, Zehetmayer S, et al. Data from the VITA Study do not support the concept of vascular depression. Am J Geriatr Psychiatry 2006;14:531-537.

15. Grool AM, van der Graaf Y, Vincken KL, Witkamp TD, Mali WP, Geerlings MI. Antidepressant use is related to larger white matter lesion volume in patients with symptomatic atherosclerotic disease: the SMART-MR Study. J Neurol 2013;260:197-206.

16. Teodorczuk A, Firbank MJ, Pantoni L, et al. Relationship between baseline white-matter changes and development of late-life depressive symptoms: 3-year results from the LADIS Study. Psychol Med 2010;40:603-610.

17. Pohjasvaara T, Leppavuori A, Siira I, Vataja R, Kaste M, Erkinjuntti T. Frequency and clinical determinants of poststroke depression. Stroke 1998;29:2311-2317.

18. Bamford J, Sandercock P, Dennis M, Burn J, Warlow C. Classification and natural history of clinically identifiable subtypes of cerebral infarction. Lancet 1991;337:1521-1526.

19. Yesavage JA, Brink TL, Rose TL, et al. Development and validation of a geriatric depression screening scale: a preliminary report. J Psychiatr Res 1982;17:37-49.

20. Lawrence AJ, Patel B, Morris RG, et al. Mechanisms of cognitive impairment in cerebral small vessel disease: multimodal MRI results from the St George's Cognition and Neuroimaging in Stroke (SCANS) Study. PLoS One 2013;8:e61014

21. Brookes RL, Hannesdottir K, Lawrence R, Morris RG, Markus HS. Brief Memory and Executive Test: evaluation of a new screening test for cognitive impairment due to small vessel disease. Age Ageing 2012;41:212-218.

22. Fazekas F, Chawluk JB, Alavi A, Hurtig HI, Zimmerman RA. MR signal abnormalities at $1.5 \mathrm{~T}$ in Alzheimer's dementia and normal aging. AJR Am J Roentgenol 1987;149:351-356.

23. Adams HP Jr, Bendixen BH, Kappelle LJ, et al. Classification of subtype of acute ischemic stroke: definitions for use in a multicenter clinical trial. TOAST. Trial of Org 10172 in Acute Stroke Treatment. Stroke 1993;24:35-41.

24. Williams LS, Weinberger M, Harris LE, Biller J. Measuring quality of life in a way that is meaningful to stroke patients. Neurology 1999;53:1839-1843.

25. Rankin J. Cerebral vascular accidents in patients over the age of 60: II: prognosis. Scott Med J 1957;2:200-215.

26. Mahoney FI, Barthel DW. Functional evaluation: the Barthel Index. Md State Med J 1965;14:61-65.

27. Pantoni L, Basile AM, Pracucci G, et al. Impact of agerelated cerebral white matter changes on the transition to disability: the LADIS Study: rationale, design and methodology. Neuroepidemiology 2005;24:51-62.

28. Jenkinson M, Smith S. A global optimisation method for robust affine registration of brain images. Med Image Anal 2001;5:143-156.

29. Neeman M, Freyer JP, Sillerud LO. A simple method for obtaining cross-term-free images for diffusion anisotropy studies in NMR microimaging. Magn Reson Med 1991; 21:138-143.

30. Smith SM, Jenkinson M, Johansen-Berg H, et al. Tractbased spatial statistics: voxelwise analysis of multi-subject diffusion data. Neuroimage 2006;31:1487-1505.

31. O'Brien JT, Firbank MJ, Krishnan MS, et al. White matter hyperintensities rather than lacunar infarcts are associated with depressive symptoms in older people: the LADIS Study. Am J Geriatr Psychiatry 2006;14:834-841.

32. Alexopoulos GS. The vascular depression hypothesis: 10 years later. Biol Psychiatry 2006;60:1304-1305.

33. Alexopoulos GS, Bruce ML, Silbersweig D, Kalayam B, Stern E. Vascular depression: a new view of late-onset depression. Dialogues Clin Neurosci 1999;1:68-80. 


\section{Neurology}

Depression in small-vessel disease relates to white matter ultrastructural damage, not disability

Rebecca L. Brookes, Vanessa Herbert, Andrew J. Lawrence, et al.

Neurology 2014;83;1417-1423 Published Online before print September 17, 2014

DOI 10.1212/WNL.0000000000000882

This information is current as of September 17, 2014

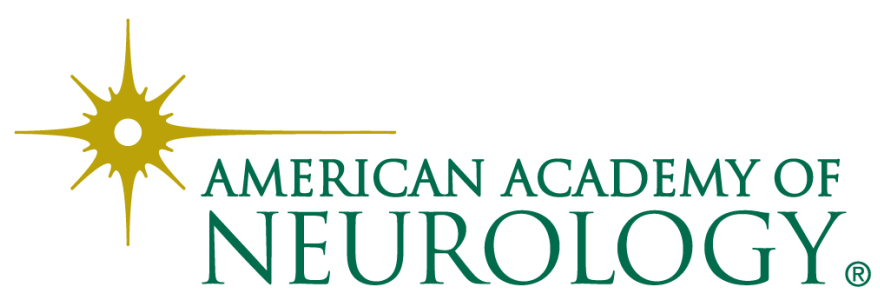




\section{Updated Information \& Services}

\section{Supplementary Material}

References

Citations

Subspecialty Collections

Permissions \& Licensing

Reprints including high resolution figures, can be found at: http://n.neurology.org/content/83/16/1417.full

Supplementary material can be found at: http://n.neurology.org/content/suppl/2014/09/17/WNL.0000000000000 882.DC1

This article cites 33 articles, 6 of which you can access for free at: http://n.neurology.org/content/83/16/1417.full\#ref-list-1

This article has been cited by 3 HighWire-hosted articles: http://n.neurology.org/content/83/16/1417.full\#\#otherarticles

This article, along with others on similar topics, appears in the following collection(s):

\section{All Cerebrovascular disease/Stroke}

http://n.neurology.org/cgi/collection/all_cerebrovascular_disease_strok e

Depression

http://n.neurology.org/cgi/collection/depression

MRI

http://n.neurology.org/cgi/collection/mri

Neuropsychological assessment

http://n.neurology.org/cgi/collection/neuropsychological_assessment

Information about reproducing this article in parts (figures,tables) or in its entirety can be found online at:

http://www.neurology.org/about/about_the_journal\#permissions

Information about ordering reprints can be found online:

http://n.neurology.org/subscribers/advertise

Neurology ${ }^{\circledR}$ is the official journal of the American Academy of Neurology. Published continuously since 1951, it is now a weekly with 48 issues per year. Copyright @ 2014 American Academy of Neurology. All rights reserved. Print ISSN: 0028-3878. Online ISSN: 1526-632X.

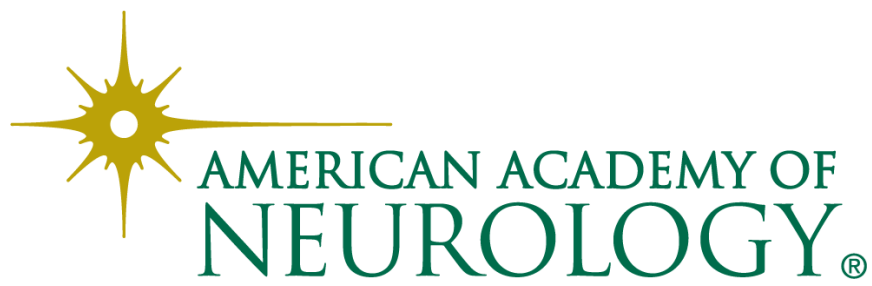

